\title{
Occurrence of Salmonella Typhimurium and its monophasic variant (4, [5],12:i:-) in healthy and clinically ill pigs in northern Italy
}

Mario D'Incau ${ }^{1 *}$ (D, Cristian Salogni ${ }^{1}$, Stefano Giovannini ${ }^{1}$, Jessica Ruggeri ${ }^{1}$, Federico Scali ${ }^{1}$, Matteo Tonni ${ }^{1}$, Nicoletta Formenti ${ }^{1}$, Flavia Guarneri ${ }^{1}$, Paolo Pasquali ${ }^{2}$ and Giovanni Loris Alborali ${ }^{1}$

\begin{abstract}
Background: The serovar Typhimurium (4, [5],12:i:1,2), is the most frequently isolated serovar in case of salmonellosis in pigs in Europe and its monophasic variant (4, [5],12:i:-) has been increasingly responsible for Salmonella outbreaks in humans. A total of 25,215 samples were collected, during the years 2002-2017, from 1359 pig farms located in Northern Italy. Samples were collected from different material sources including fecal samples, rectal swabs, gut content and different organs.

Results: Salmonella was isolated in $15.80 \%$ of samples and, among the isolates, 733 were typed as Salmonella Typhimurium (ST) or its monophasic variant (MST). Over time, there was an increase of isolation of MST which outnumbered ST. Most of the strains were isolated in animals during the weaning stage and the growing fattening period whereas the clinical cases were mainly present in young pigs after weaning.

Conclusions: This study confirms the presence of ST and MST in pig farms although, considering the total of isolated serotypes, with lower percentages than previously reported.

In the last few years, ST has increasingly been replaced by MST suggesting that MST has a competitive advantage over ST, probably due to its different antigenicity and pathogenicity which renders the infection stealthier to recognize and control.
\end{abstract}

Keywords: Salmonella Typhimurium, Pig, Epidemiology

\section{Background}

Pigs can be infected with a broad range of Salmonella serotypes some of which can cause clinical disease and, frequently, can contaminate meat products [1].

Apart from the serovar Choleraesuis of S. enterica subsp. enterica, a host-adapted serovar usually isolated in cases of septicemia, the serovar Typhimurium, is now

\footnotetext{
* Correspondence: mario.dincau@izsler.it

'Istituto Zooprofilattico Sperimentale della Lombardia e dell'Emilia-Romagna "Bruno Ubertini", via Bianchi 9, 25124 Brescia, Italy

Full list of author information is available at the end of the article
}

the most frequently isolated serovar in case of illness in pigs in Europe [2-4] and in the United States [5].

Clinically ill pigs can develop, in the most severe cases, enterocolitis and exhibit diarrhea and dehydration. The disease most commonly develops in pigs with concurrent debilitating diseases, in conditions of poor hygiene that allow exposure to high doses of the organism, or in immunologically naive pigs. Mortality is variable. Most pigs have a complete recovery and eliminate the organism, but others may remain carriers and intermittent shedders for several months [1].

(c) The Author(s). 2021 Open Access This article is licensed under a Creative Commons Attribution 4.0 International License, which permits use, sharing, adaptation, distribution and reproduction in any medium or format, as long as you give appropriate credit to the original author(s) and the source, provide a link to the Creative Commons licence, and indicate if changes were made. The images or other third party material in this article are included in the article's Creative Commons. licence, unless indicated otherwise in a credit line to the material. If material is not included in the article's Creative Commons licence and your intended use is not permitted by statutory regulation or exceeds the permitted use, you will need to obtain permission directly from the copyright holder. To view a copy of this licence, visit http://creativecommons.org/licenses/by/4.0/ The Creative Commons Public Domain Dedication waiver (http://creativecommons.org/publicdomain/zero/1.0/) applies to the data made available in this article, unless otherwise stated in a credit line to the data. 
The monophasic variant of Salmonella Typhimurium (4, [5],12:i:-) has been increasingly responsible for Salmonella outbreaks in humans, being the third (after the serovars Salmonella Enteritidis and Salmonella Typhimurium) most commonly reported serovar in the EU in 2012 [6], and frequently reported across the world [7, 8]. This serovar, strongly associated with swine food chain, especially in Europe [9], was rarely identified before the mid-1990s but its isolation in both animals and humans, has increased in the last 20 years [4, 10-12].

Salmonella prevalence varies widely among farms and at different growth stages within the same farm and, due to the high number of factors and the complex relationships among pathogen and host, definitive understanding of the transmission, shedding and carrier states of salmonellae are still difficult [1].

The aim of this study is to describe and evaluate the occurrence, over a 15-year period, of Salmonella Typhimurium (ST) and its monophasic variant Salmonella enterica subsp. enterica 4, [5],12:i:- (MST) in pigs and its association with clinical conditions.

\section{Materials and methods}

\section{Strains isolation}

A total of 25,215 samples were collected, during the years 2002-2017, from 1359 pig farms located in Northern Italy where clinical enteric forms or cases of on-farm mortality occurred. In particular, in each farm around 20 samples per year were collected either from living animals (fecal samples or rectal swabs) or from carcasses (gut content and different organs like spleen, liver and lymph nodes collected at necropsy) and sent to our lab by farm vets.

The isolation and identification of Salmonella isolates were carried out always by the same lab, initially in accordance with ISO 6579:2002 and later, for samples collected since 2007, in accordance with ISO 6579:2007 amendment 1. Briefly, the samples were pre-enriched with Buffered Peptone Water (BPW) and incubated at $37^{\circ} \mathrm{C} \pm 1{ }^{\circ} \mathrm{C}$ for $18 \pm 2 \mathrm{~h}$. The samples were then transferred, for enrichment, to Rappaport - Vassiliadis Soya Broth (RVS), incubated at $41.5^{\circ} \mathrm{C} \pm 1{ }^{\circ} \mathrm{C}$ for $24 \pm 3 \mathrm{~h}$, and Mueller - Kauffmann Tetrathionate with Novobiocin Broth (MKTTn), incubated at $37^{\circ} \mathrm{C} \pm 1{ }^{\circ} \mathrm{C}$ for $24 \pm 3 \mathrm{~h}$ (for 2002-2007 samples: ISO 6579:2007), and (for 20072017 samples: ISO 6579:2007 amendment 1) to a Modified Semisolid Rappaport - Vassiliadis (MSRV) agar medium incubated at $41.5^{\circ} \mathrm{C} \pm 1{ }^{\circ} \mathrm{C}$ for $24 \pm 3 \mathrm{~h}$. MSRV agar plates were incubated for further $24 \pm 3 \mathrm{~h}$ if negative. Enrichment cultures were used to inoculate two solid media incubated at $37^{\circ} \mathrm{C} \pm 1{ }^{\circ} \mathrm{C}$ for $24 \pm 3 \mathrm{~h}$ : Xylose Lysine Deoxycholate agar (XLD) and Brilliant Green Agar (BGA).
Colonies of presumptive Salmonella were sub-cultured on Triple Sugar Iron (TSI) agar at $37^{\circ} \mathrm{C} \pm 1{ }^{\circ} \mathrm{C}$ for $18 \pm 2$ $\mathrm{h}$ and further, in accordance with ISO 6579:2007, identified biochemically and confirmed as Salmonella by slide agglutination using a polyvalent $\mathrm{O}$ antiserum.

\section{Strain serotyping}

The complete serological characterization of Salmonella was performed by slide agglutination for the determination of somatic antigens, while, for the determination of flagellar antigens, the method of tube agglutination was followed according to the Spicer [13] technique, modified by Morris et al. [14].

In particular, the characterization of monophasic variant of Salmonella Typhimurium, was performed through two consecutive phase inversions by passaging through a U-shaped glass tube containing semisolid agar with $\mathrm{H}: \mathrm{i}$ antiserum. The isolates that still did not display the second phase after the first and the second passage were considered, phenotypically, monophasic.

\section{Phage-typing}

Phage-typing was performed at the Italian National Reference Centre for Animal Salmonellosis according to Anderson et al. [15]. Typing of MST strains started in 2011 and for this reason only 225 isolates were typed. The total number of typed ST strains was 235 .

\section{Clinical case definition}

We considered a "clinical case" (C) as an illness of variable severity manifested by enteric signs with presence of Salmonella and in absence of isolation of other enteric pathogens. When Salmonella isolation occurred and no enteric signs were shown the condition was referred as a "non-clinical case" (NC).

\section{Statistical methods}

Statistical analysis was performed using GraphPad 6.0 for MAC OS X (GraphPad Software Inc.; San Diego; CA) and SAS (SAS Institute, Inc., Cary, North Carolina) softwares. Differences in proportions were estimated using Fisher's exact test. Differences in ST and MST prevalence among years were evaluated through Chisquared test. A $P$ value less than 0.05 was considered statistically significant while a value between 0.05 and 0.1 will be defined as trend.

\section{Results}

Serotyping results

Salmonella was isolated from 3983 out of 25,215 fecal samples (15.80\%). Among the isolates, 246 were typed as Salmonella Typhimurium and 487 as its monophasic variant. Two hundred eighty-five out of 1359 farms (20.97\% of the total) resulted positive for the serovars 
investigated in this study. The distribution of the isolates, during the considered period, is showed in Table 1 and Fig. 1. Overall, it is possible to see two distinct phases. The number of ST isolates were slightly greater than that of MST isolates from 2002 to 2007. Thereafter, since 2008, it is possible to see a steady increase of the presence of MST over ST. Prevalence of both ST $\left(\chi^{2}{ }_{15}=\right.$ 363.3019, $p<0.0001)$ and MST $\left(x^{2}{ }_{15}=217.5584, p<\right.$ 0.0001 ) varied significantly depending on the study year.

Five hundred seventeen out of 733 collected isolates came from pigs whose different ages were known: amongst them, most of the MST and ST strains were isolated in animals during the weaning (since 30 days of age till $25 / 30 \mathrm{~kg}$ weigh) stage $(n=311 ; 60.15 \%)$ and the growing (25/30 kg - $60 \mathrm{~kg}$ weigh) - fattening (60 kg weigh to slaughtering) period ( $n=177 ; 34.24 \%)$ whereas the number of isolates from breeders $(n=11 ; 2.13 \%)$ as well as from suckling piglets $(n=18 ; 3.48 \%)$ was low. Similar patterns of distribution were observed considering ST and MST separately (Fig. 2).

Clinical signs were associated with 114 out of 246 (46.34\%) isolates of ST and 184 out of 487 (37.78\%) isolates of MST (Table 2). Although it seems that the association of MST to clinical signs is lower than in ST, the difference only approached the statistical significance $(P=0.08)$.

Figure 3 shows the percentage of strains (on the total of MST and ST strains) associated with clinical illness

Table 1 Number of MST and ST isolates and related percentages on the total of positive samples

\begin{tabular}{|c|c|c|c|c|c|c|c|}
\hline \multirow[t]{2}{*}{ Year } & \multirow{2}{*}{$\begin{array}{l}\text { Total } \\
\text { positive } \\
\text { samples }\end{array}$} & \multicolumn{2}{|l|}{ ST } & \multicolumn{2}{|l|}{ MST } & \multicolumn{2}{|c|}{$S T+M S T$} \\
\hline & & $n$ & $\%$ & $n$ & $\%$ & $n$ & $\%$ \\
\hline 2002 & 108 & 38 & 35.19 & 18 & 16.67 & 56 & 51.85 \\
\hline 2003 & 164 & 16 & 9.76 & 19 & 11.59 & 35 & 21.34 \\
\hline 2004 & 106 & 24 & 22.64 & 11 & 10.38 & 35 & 33.02 \\
\hline 2005 & 72 & 19 & 26.39 & 10 & 13.89 & 29 & 40.28 \\
\hline 2006 & 268 & 28 & 10.45 & 18 & 6.72 & 46 & 17.16 \\
\hline 2007 & 325 & 18 & 5.54 & 18 & 5.54 & 36 & 11.08 \\
\hline 2008 & 262 & 32 & 12.21 & 45 & 17.18 & 77 & 29.39 \\
\hline 2009 & 196 & 6 & 3.06 & 36 & 18.37 & 42 & 21.43 \\
\hline 2010 & 272 & 6 & 2.21 & 21 & 7.72 & 27 & 9.93 \\
\hline 2011 & 416 & 8 & 1.92 & 15 & 3.61 & 23 & 5.53 \\
\hline 2012 & 834 & 17 & 2.04 & 84 & 10.07 & 101 & 12.11 \\
\hline 2013 & 339 & 10 & 2.95 & 57 & 16.81 & 67 & 19.76 \\
\hline 2014 & 145 & 16 & 11.03 & 61 & 42.07 & 77 & 53.10 \\
\hline 2015 & 176 & 3 & 1.70 & 39 & 22.16 & 42 & 23.86 \\
\hline 2016 & 231 & 5 & 2.16 & 28 & 12.12 & 33 & 14.29 \\
\hline 2017 & 69 & 0 & 0.00 & 7 & 10.14 & 7 & 10.14 \\
\hline Total & 3983 & 246 & 6.18 & 487 & 12.23 & 733 & 18.40 \\
\hline
\end{tabular}

referred to the single production stage. Most of the clinical cases were present in young pigs after weaning, while in fatteners and breeders the occurrence of clinical signs were lower. When infected with MST, clinical signs were present in $45.17 \%$ (103/228) and 25.95\% (34/ 131) of pigs, in weaners and growers-fatteners respectively, while in case of isolation of ST, clinical signs were present in $53.01 \%(44 / 83)$ and $43.48 \%(20 / 46)$ of pigs, respectively.

\section{Phage typing results}

The isolates belonged to 23 different phage types (Table 3), and eight of them were common to both serovars. The most frequently isolated phage types were DT193 (62 isolates) and DT120 (47 isolates), followed by U311 (45 isolates) and U302 (29 isolates). Other types found were DT104 (18 isolates), DT20A (16 isolates) and DT208 (11 isolates). DT193 was the most frequent type among MST strains while U302 was the most common among ST strains. Forty-nine isolates showed a pattern which did not conform (RDNC) to any defined pattern, and 149 could not be phage typed (NT).

\section{Discussion}

The results presented here were obtained from farms, located in Northern Italy in a high-density pig population area, and checked when clinical enteric forms or cases of on-farm mortality occurred. We focused on ST and MST, considering the prominent role of these two serovars in the pig population $[4,12]$.

ST and MST represented $12.23 \%$ and 6.18, respectively of the Salmonella serovars isolated, low percentages compared to those from other reports. Indeed, recent studies suggested that ST and MST represent between 40 and $50 \%$ of the Italian isolates, with MST increasing from 9.66 to $46.34 \%$ in the last 10 years [16, 17]. A similar increasing has also been reported in other countries [12]. Although it may seem that, in this study, a lower prevalence than those available in the literature to date were recorded, a comparison can not actually be made because in this study we used a clinical sampling with the presence of the enteric clinical form in the herd as inclusion criterion. Therefore, the fact that our sampling was not randomly performed, but following clinical criteria, does not make possible a comparison with other studies. The distribution of the studied serovars, during the considered period, highlighted a predominance of ST on MST in the first period and, since 2008, a reversion of this tendency with MST becoming more predominant over the following years. Indeed after 2009, MST subsequent recorded peaks were likely related to cyclic outbreaks and to the hypothesized pigs' role of reservoir for this serovar [18]. 


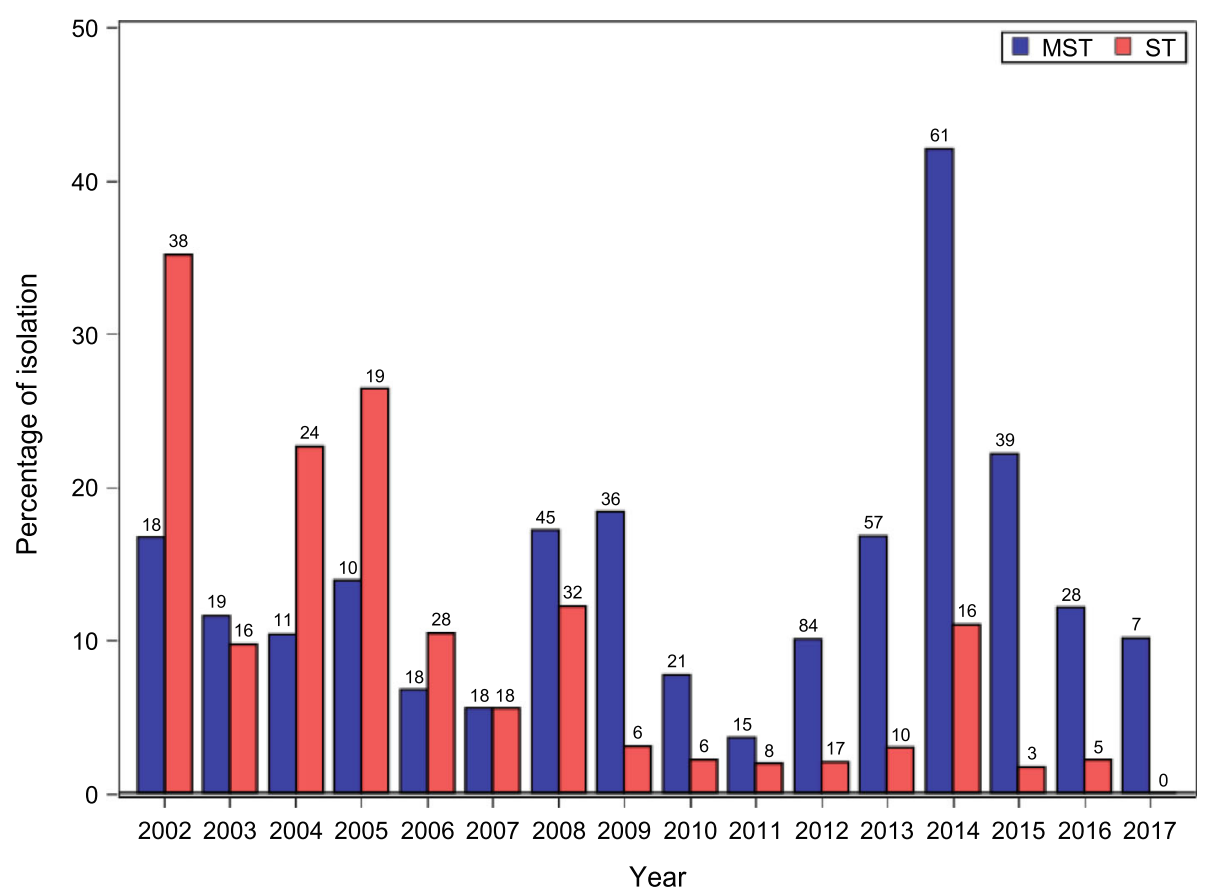

Fig. 1 Distribution of the isolates (percentages on the total of positive samples) of Salmonella Typhimurium (ST) and its monophasic variant (MST), during the period of the study (2002-2017)

The data reported here are in accordance with recent reports where the increasing prevalence of MST is well documented, in particular in the United Kingdom, Poland and Malta $[6,19,20]$. In the United Kingdom, MST represented $60.7 \%$ of the Salmonella isolates obtained from a surveillance program in pigs in 2015 [21].
It is conceivable to hypothesize that MST has a selective advantage over ST. It was suggested that a number of factors (i.e. involvement of prophages and antigenic changes) can cause a reduced immune response to MST in herds when compared to ST [4]. More recently, a comparative whole-genome sequencing and

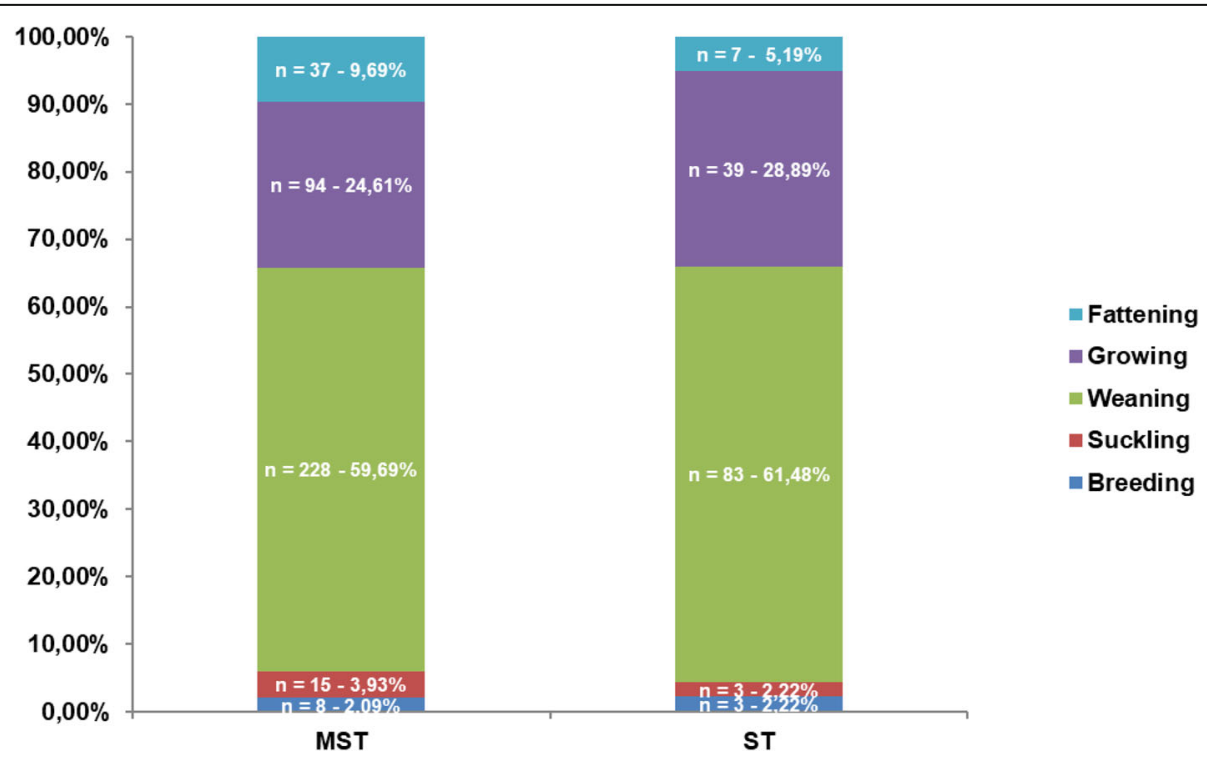

Fig. 2 Distribution of the isolates of Salmonella Typhimurium (ST) and its monophasic variant (MST) related to the production stages 
Table 2 Association between clinical conditions and the presence of Salmonella Typhimurium (ST) and its monophasic variant (MST)

\begin{tabular}{llll}
\hline & $\begin{array}{l}\text { Clinical signs present } \\
\text { (number of isolates) }\end{array}$ & $\begin{array}{l}\text { Clinical signs absent } \\
\text { (number of isolates) }\end{array}$ & $\begin{array}{l}\text { Total } \\
\text { number of isolates }\end{array}$ \\
\hline ST & 114 & 132 & 246 \\
MST & 184 & 303 & 487 \\
Total & $\mathbf{2 9 8}$ & $\mathbf{4 3 5}$ & $\mathbf{7 3 3}$ \\
\hline
\end{tabular}
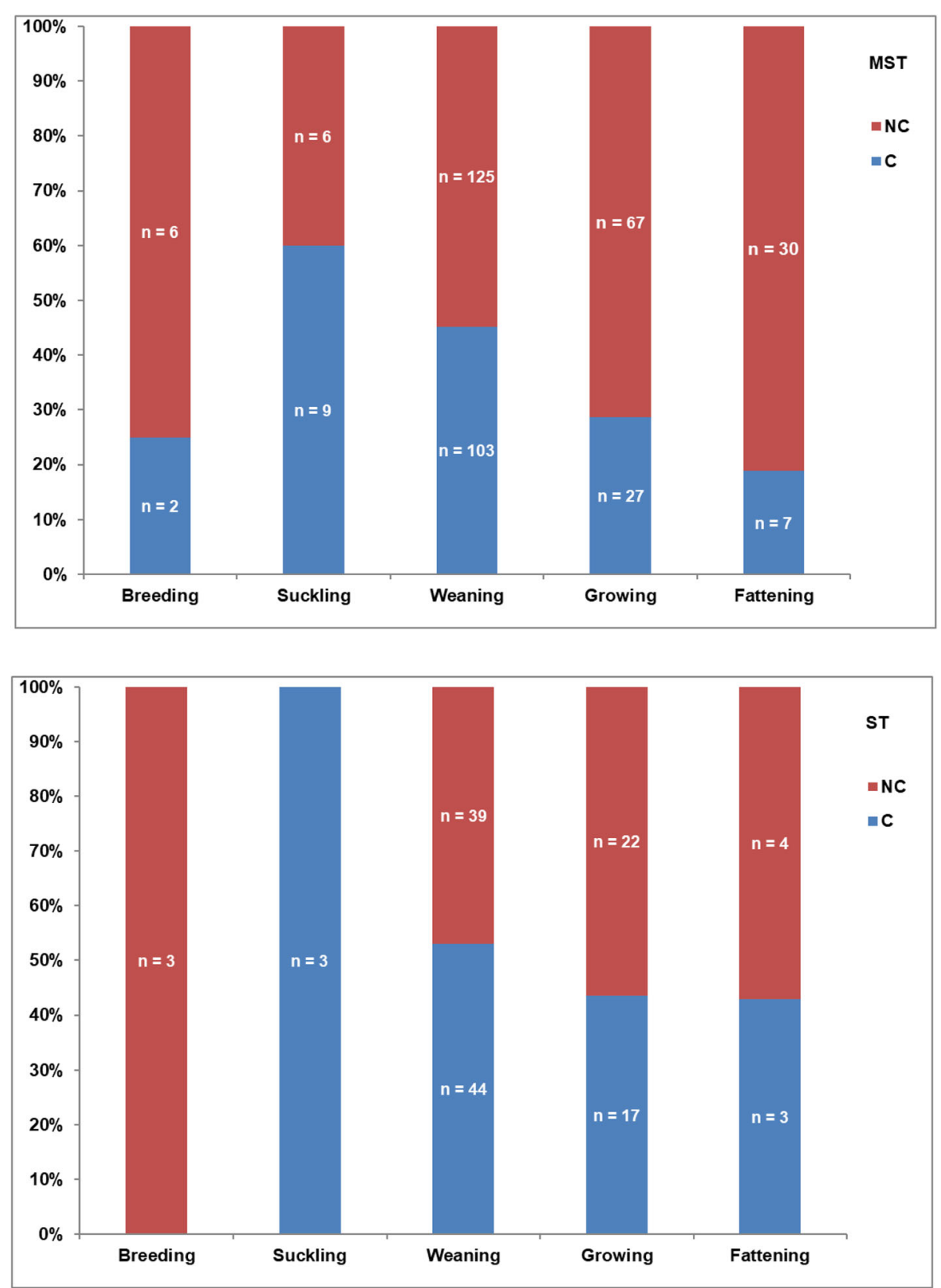

Fig. 3 Percentage of the isolates of Salmonella Typhimurium (ST) and its monophasic variant (MST) associated (C) or not associated (NC) with clinical illness related to the production stages 
Table 3 Phage-types associated with isolates of Salmonella Typhimurium (ST) and its monophasic variant (MST) and related percentages on the total of each phage-type

\begin{tabular}{|c|c|c|c|c|c|}
\hline \multirow{2}{*}{$\begin{array}{l}\text { Phage } \\
\text { type }\end{array}$} & \multicolumn{2}{|c|}{ MST } & \multicolumn{2}{|c|}{ ST } & \multirow{2}{*}{$\begin{array}{l}\text { Total } \\
\text { phage- } \\
\text { typed }\end{array}$} \\
\hline & $n$ & $\%$ & $n$ & $\%$ & \\
\hline DT193 & 50 & 80.65 & 12 & 19.35 & 62 \\
\hline DT120 & 36 & 76.60 & 11 & 23.40 & 47 \\
\hline U311 & 28 & 62.22 & 17 & 37.78 & 45 \\
\hline U302 & 4 & 13.79 & 25 & 86.21 & 29 \\
\hline DT104 & & 0 & 18 & 100.00 & 18 \\
\hline DT20A & 13 & 81.25 & 3 & 18.75 & 16 \\
\hline DT208 & & 0 & 11 & 100.00 & 11 \\
\hline DT110 & 1 & 14.29 & 6 & 85.71 & 7 \\
\hline DT104B & & 0 & 5 & 100.00 & 5 \\
\hline DT12 & & 0 & 5 & 100.00 & 5 \\
\hline DT7VAR & & 0 & 3 & 100.00 & 3 \\
\hline DT1 & 1 & 50.00 & 1 & 50.00 & 2 \\
\hline DT32 & $1 /$ & 50.00 & 1 & 50.00 & 2 \\
\hline DT138 & & 0 & 1 & 100.00 & 1 \\
\hline DT193A & 1 & 100.00 & & 0 & 1 \\
\hline DT194 & & 0 & 1 & 100.00 & 1 \\
\hline DT195 & & 0 & 1 & 100.00 & 1 \\
\hline DT27 & & 0 & 1 & 100.00 & 1 \\
\hline DT36 & & 0 & 1 & 100.00 & 1 \\
\hline DT7 & & 0 & 1 & 100.00 & 1 \\
\hline DT7A & 1 & 100.00 & & 0 & 1 \\
\hline DT99 & & 0 & 1 & 100.00 & 1 \\
\hline U310 & & 0 & 1 & 100.00 & 1 \\
\hline
\end{tabular}

phylogenomic analysis of MST isolates from the United Kingdom and Italy during the period 2005-2012, revealed a high level of microevolution that may affect antigenicity, pathogenicity, and transmission [22].

Although the increase of the number of the MST isolates coincides with the revision of the isolation method, in order to rule out any influence of the testing method upon the results, it is important to highlight that the analyses were performed according to ISO methods: the change of the enrichment media can not affect the suitability of detecting any of the known motile Salmonella serovars [23]. The replacements of two enrichment broth media with a semi-solid medium leads, on the other hand, to a better selection on the background flora able to grow in the broths and potentially able to mask the isolation of Salmonella strains [23].

When considering the production stage, both ST and MST showed their highest presence in the weaning and growing period as reported previously [24, 25]. A comparison between the prevalence of ST and MST in different production stages showed no significant differences. Overall, these findings suggest a higher level of susceptibility in younger pigs, irrespective of the serovars involved. Pigs can become infected at any production stage but the decline of maternal antibodies after weaning makes younger pigs more susceptible to the infection [26].

When considering the association between clinical signs and isolates, we observed that clinical signs were associated more to ST than to MST and that most of clinical cases were present in young pigs after weaning. These data, although only approaching significance, are supportive of a competitive advantage of MST over ST.

The phage-typing highlighted the prevalence of four types representing about $70 \%$ of the typed isolates (DT193, DT120, U311, U302) and this has been a common feature of European isolates for the last 20 years $[11,27,28]$. DT193 has to be regarded as an important phage type also for ST, considering its increase in Europe in the last years [29] and its role in human cases of salmonellosis.

\section{Conclusions}

In conclusion, this study confirms the presence of ST and MST in pig farms although, considering the total of isolated serotypes, with lower percentages than previously reported.

In the last few years, ST has increasingly been replaced by MST suggesting that MST has a competitive advantage over ST, probably due to its different antigenicity and pathogeneicity which renders the infection stealthier to recognize and control. More detailed studies should be undertaken to assess the mechanisms underpinning the competitive advantage of MST over ST in pigs.

\section{Abbreviations}

ST: Salmonella Typhimurium; MST: Salmonella Typhimurium monophasic variant; EU: European Union; RDNC: Result does not conform; NT: Not typed; ISO: International Standard Organization; BPW: Buffered Peptone Water;

RVS: Rappaport - Vassiliadis Soya; MKTTn: Mueller - Kauffmann Tetrathionate with Novobiocin; MSRV: Modified Semisolid Rappaport - Vassiliadis;

XLD: Xylose Lysine Deoxycholate; BGA: Brilliant Green Agar; TSI: Triple Sugar Iron; C: Clinical case; NC: Non-clinical case

\section{Acknowledgements}

The authors want to thank Laura Birbes, Adelaide Braga, Stefania Folgoni, Giuseppe Orlandi, Francesca Pellegrinelli, and Alberto Tiraboschi for their excellent technical assistance.

\section{Authors' contributions}

GLA, MD: experimental design. SG, JR, CS, FS, MT, NF, FG: collection and analysis of the samples. MD: text elaboration of the manuscript. MD, PP, NF: discussion and interpretation of the results. GLA: supervision of the activities. The author(s) read and approved the final manuscript.

\section{Funding}

Not applicable.

\section{Availability of data and materials}

The datasets used and/or analysed during the current study are available from the corresponding author on reasonable request. The dataset supporting the conclusions of this article is included within the article. 


\section{Declarations}

\section{Ethics approval and consent to participate}

All farms enrolled in the study followed their own management practices. No protocol approval of the ethical committee of Istituto Zooprofilattico Sperimentale della Lombardia e dell'Emilia-Romagna "Bruno Ubertini" was required as samples were collected at slaughterhouse after processing. Informed consent was received from all animal owners.

\section{Consent for publication}

Not applicable.

\section{Competing interests}

The authors declare that there are no potential conflicts of interest or any financial or personal relationships with other people or organizations that could inappropriately bias conduct and findings of this study.

\section{Author details}

'Istituto Zooprofilattico Sperimentale della Lombardia e dell'Emilia-Romagna "Bruno Ubertini", via Bianchi 9, 25124 Brescia, Italy. ${ }^{2}$ Department of Food Safety, Nutrition and Veterinary Public Health, Istituto Superiore di Sanità, viale Regina Elena 299, 00161 Roma, Italy.

\section{Received: 9 December 2020 Accepted: 19 April 2021}

\section{Published online: 26 April 2021}

\section{References}

1. Carlson SA, Barnhill AE, Griffth RW. Salmonellosis. In: Zimmerman JJ, Karriker LA, Ramirez A, Schwartz KJ, Stevenson GW, editors. Diseases of swine. 10th ed. Chichester: Wiley-Blackwell; 2012. p. 821-33.

2. García-Feliz C, Collazos JA, Carvajal A, Herrera S, Echeita MA, Rubio P. Antimicrobial resistance of Salmonella enterica isolates from apparently healthy and clinically ill finishing pigs in Spain. Zoonoses Public Health. 2008:55(4):195-205. https://doi.org/10.1111/j.1863-2378.2008.01110.x.

3. Miller AJ, Twomey DF, Davies RH, Teale CJ, Williamson SM, Reichel R, et al. Salmonella serovars and antimicrobial resistance patterns on a sample of high seroprevalence pig farms in England and Wales (2003-2008). Zoonoses Public Health. 2011;58(8):549-59. https://doi.org/10.1111/j.1863-2378.2011. 01402.x.

4. Mueller-Doblies D, Speed K, Davies RH. A retrospective analysis of Salmonella serovars isolated from pigs in Great Britain between 1994 and 2010. Prev Vet Med. 2013;110(3-4):447-55. https://doi.org/10.1016/j. prevetmed.2013.02.023.

5. Foley SL, Lynne AM. Food animal-associated Salmonella challenges: pathogenicity and antimicrobial resistance. J Anim Sci. 2008;86(14 Suppl): E173-87. https://doi.org/10.2527/jas.2007-0447.

6. European Food Safety Authority (EFSA), European Centre for Disease Prevention and Control (ECDC). The European Union summary report on trends and sources of zoonoses, zoonotic agents and food-borne outbreaks in 2012. EFSA J. 2014;12:3547.

7. Soyer Y, Moreno Switt A, Davis MA, Maurer J, McDonough PL, Schoonmaker-Bopp DJ, et al. Salmonella enterica serotype 4,5,12:i-; an emerging Salmonella serotype that represents multiple distinct clones. J Clin Microbiol. 2009;47(11):3546-56. https://doi.org/10.1128/JCM.00546-09.

8. Tamang MD, Gurung M, Nam HM, Moon DC, Kim SR, Jang GC, et al. Prevalence and characterization of Salmonella in pigs from conventional and organic farms and first report of S. serovar 1,4,[5],12:i:- from Korea. Vet Microbiol. 2015;178(1-2):119-24. https://doi.org/10.1016/.jvetmic.2015.05.005.

9. Sun H, Wan Y, Du P, Bai L. The epidemiology of monophasic Salmonella Typhimurium. Foodborne Pathog Dis. 2020;17(2):87-97. https://doi.org/10.1 089/fpd.2019.2676.

10. Dionisi AM, Graziani C, Lucarelli C, Filetici E, Villa L, Owczarek S, et al. Molecular characterization of multidrug-resistant strains of Salmonella enterica serotype Typhimurium and monophasic variant (S. 4,[5],12:i:-) isolated from human infections in Italy. Foodborne Pathog Dis. 2009;6(6): 711-7. https://doi.org/10.1089/fpd.2008.0240.

11. Switt Al, Soyer Y, Warnick LD, Wiedmann M. Emergence, distribution, and molecular and phenotypic characteristics of Salmonella enterica serotype 4,5,12:i. Foodborne Pathog Dis. 2009;6(4):407-15. https://doi.org/10.1089/ fpd.2008.0213.
12. Mueller-Doblies D, Speed KCR, Kidd S, Davies RH. Salmonella Typhimurium in livestock in Great Britain - trends observed over a 32-year period. Epidemiol Infect. 2018;146(4):409-22. https:/doi.org/10.1017/5095026881800002X.

13. Spicer CC. A quick method of identifying Salmonella $\mathrm{H}$ antigens. J Clin Pathol. 1956;9(4):378-9. https://doi.org/10.1136/jcp.9.4.378.

14. Morris GK, Steele CD, Wells JG. Evaluation of plastic multi-well plates for serological screening of Salmonella cultures with Spicer-Edwards pooled antisera. Appl Microbiol. 1972;24(5):846-8. https://doi.org/10.1128/AM.24.5.84 6-848.1972.

15. Anderson ES, Ward LR, Saxe MJ, de Sa JD. Bacteriophage-typing designations of Salmonella typhimurium. J Hyg (Lond). 1977;78(2):297-300. https://doi.org/10.1017/S0022172400056187.

16. Ricci A, Mancin M, Barco L, Cibin V. Enter-Vet Report 2007-2008. Legnaro: Centro di Referenza Nazionale per le Salmonellosi, Istituto Zooprofilattico Sperimentale delle Venezie; 2009. Available from: http://www.izsvenezie.it/ documenti/temi/salmonellosi/enter-vet/entervet-report-2007-2008.pdf (Accessed 24 Apr 2020

17. Cibin V, Mancin M, Ricci A. Entervet report 2015. Legnaro: Centro di Referenza Nazionale per le Salmonellosi, Istituto Zooprofilattico Sperimentale delle Venezie; 2016. Available at: http://www.izsvenezie.it/ documenti/temi/salmonellosi/enter-vet/entervet-report-2015.pdf (Accessed 24 Apr 2020).

18. Mandilara G, Lambiri M, Polemis M, Passiotou M, Vatopoulos A. Phenotypic and molecular characterisation of multiresistant monophasic Salmonella Typhimurium. Euro Surveill. 2013;18:20496 Available from: http://www. eurosurveillance.orgNiewArticle.aspx? Articleld = 20496 (Accessed 23 Mar 2021).

19. European Food Safety Authority (EFSA) European Centre for Disease Prevention and Control (ECDC). The European Union summary report on trends and sources of zoonoses, zoonotic agents and food-borne outbreaks in 2014. EFSA J. 2015:13:4329.

20. European Food Safety Authority (EFSA) European Centre for Disease Prevention and Control (ECDC). The European Union summary report on trends and sources of zoonoses, zoonotic agents and food-borne outbreaks in 2015. EFSA J. 2016;14:4634.

21. Lawes J, Kidd S. Salmonella in livestock production in Great Britain. Animal and Plant Health Agency. Available from: https:/www.gov.uk/government/ publications/salmonella-in-livestock-production-in-great- britain-2015 (Accessed 24 Apr 2020).

22. Petrovska L, Mather AE, AbuOun M, Branchu P, Harris SR, Connor T, et al. Microevolution of monophasic Salmonella Typhimurium during epidemic, United Kingdom, 2005-2010. Emerg Infect Dis. 2016;22(4):617-24. https://doi. org/10.3201/eid2204.150531.

23. EFSA Panel on Biological Hazards (BIOHAZ). Scientific Opinion on monitoring and assessment of the public health risk of "Salmonella Typhimurium-like" strains. EFSA J. 2010;8:1826.

24. Wales AD, McLaren IM, Bedford S, Carrique-Mas JJ, Cook AJ, Davies RH. Longitudinal survey of the occurrence of Salmonella in pigs and the environment of nucleus breeder and multiplier pig herds in England. Vet Rec. 2009;165(22):648-57. https://doi.org/10.1136/vr.165.22.648.

25. Martelli F, Andres VM, Davies R, Smith RP. Observations on the introduction and dissemination of Salmonella in three previously low prevalence status pig farms in the United Kingdom. Food Microbiol. 2018;71:129-34. https:// doi.org/10.1016/j.fm.2017.05.004

26. Pires AF, Funk JA, Bolin C. Risk factors associated with persistence of Salmonella shedding in finishing pigs. Prev Vet Med. 2014;116(1-2):120-8. https://doi.org/10.1016/j.prevetmed.2014.06.009.

27. Fernandes L, Centeno M, Belas A, Nunes T, Lopes Alves P, Couto N, et al. Immediate after birth transmission of epidemic Salmonella enterica Typhimurium monophasic strains in pigs is a likely event. J Antimicrob Chemother. 2012;67(12):3012-4. https://doi.org/10.1093/jac/dks334.

28. Fernandes $\mathrm{L}$, Centeno MM, Couto N, Nunes T, Almeida V, Alban L, et al. Longitudinal characterization of monophasic Salmonella Typhimurium throughout the pig's life cycle. Vet Microbiol. 2016;192:231-7. https://doi.org/10.1016/:vetmic.2016.07.018,

29. European Food Safety Authority (EFSA) European Centre for Disease Prevention and Control (ECDC). The European Union summary report on trends and sources of zoonoses, zoonotic agents and food-borne outbreaks in 2010. EFSA J. 2012;10:2597.

\section{Publisher's Note}

Springer Nature remains neutral with regard to jurisdictional claims in published maps and institutional affiliations. 